\title{
E-commerce adoption in ASEAN: who and where?
}

\author{
Abu H. Ayob*
}

\begin{abstract}
As an economic bloc, the Association of Southeast Asia Nations (ASEAN) aims to leverage the usage of e-commerce for the benefits of all: government, enterprises, and citizens of its member countries. However, each country varies greatly in terms of economic development and cultural factors, which explains the uneven level of e-commerce adoption in the region. This paper seeks to provide empirical evidence by integrating individual and country-level characteristics to profile e-commerce users in ASEAN. By analyzing multi-source data from 5870 individuals in six countries in 2017, the results reveal that e-commerce adoption is more prevalent among female, younger, more educated, employed, and higher income users. Also, the adoption of e-commerce is found to be stronger in societies that exhibit high individualism, low masculinity and low uncertainty avoidance. This study proposes that e-commerce adoption shall not only be explained by individual characteristics and formal institutions, but also by country-level variables and national culture.
\end{abstract}

Keywords: E-commerce adoption, ASEAN, Individual demographics, National culture

\section{Introduction}

The ability to conduct business transactions via computer networks has existed since the 1960s, yet the emergence of two companies, Amazon and eBay, in 1995 has enormously transformed the way today's businesses operate. E-commerce refers to the process of selling and purchasing goods and/or services through computer networks following the methods specifically designed for placing and acquiring orders, according to the Organisation for Economic Co-operation and Development [43]. In contrast to traditional retail, most e-commerce activities are handled virtually during pre-purchase (i.e., information search), purchase, and post-purchase (i.e., feedback and after-sales service) stages. Therefore, the ability to and preference for adopting e-commerce is a privilege only available to computer-literate customers.

Beyond that, the function of e-commerce has extended into other related activities such as serving as a platform for information sharing among consumers and traders

*Correspondence: abuhanifah.ayob@ukm.edu.my

Faculty of Economics and Management, The National University of Malaysia, 43600 Bangi, Selangor, Malaysia that, while easily accessible, is considered risky by many $[41,50]$. Thus, the application of e-commerce is no longer restricted by the quality of formal institutions, such as infrastructure and cyber law, but is also dependent on cultural aspects such as risk tolerance.

In synthesizing the two level of analysis, it is argued that the eventual online purchase behavior of customers is greatly explicated by their demographic characteristics and the country environment. Global e-commerce diffusion today remains uneven and the digital divide is still apparent across countries [33, 67]. Despite the fact that e-commerce is conceivably advantageous for all (governments, businesses, and customers) the prevalence of e-commerce adoption is greatly heterogeneous between nations [40]. This phenomenon demands extensive research to explore the individual and country-level factors contributing the adoption of e-commerce to ensure that the benefits offered can be fully embraced by all economies.

Thus far, many researchers have attempted to develop a framework for proposing the drivers and deterrents of e-commerce growth in a country (e.g.,[1]), in which the unit of analysis is either enterprises [67] or customers 
$[36,61,66]$. Despite the advancement, there is a dearth of cross-country studies of e-commerce, mostly due to the lack of effort to integrate individual and macro-level factors for analysis in a single model. Instead, existing work is mostly fragmented, focusing on who e-commerce users are (i.e., personal and cognitive-psychological attributes of consumers [66]) or where e-commerce users live (i.e., physical infrastructure and rule of law in a country [39, 44]). This approach, though meriting acknowledgement, neglects to solve either puzzle and has not adequately considered individual and country drivers simultaneously to explain the rate of e-commerce adoption across nations. There is a deficit in knowledge especially in the context of a regional bloc like the Association of Southeast Asia Nations (ASEAN), where the common goal is to narrow the digital gap while disseminating the benefits of e-commerce particularly among consumers in all country members.

In attempt to offer empirical and practical insights, this research integrates multilevel factors and examines the relationship toward e-commerce adoption in ASEAN. Specifically, the empirical approach tests individual demographics (age, gender, education level, employment status, and income level) and national culture (power distance, individualism, masculinity, and uncertainty avoidance), for explaining the propensity to buy things online among 5870 consumers from six ASEAN countries in 2017.

The contributions of this study are notable for academics and practitioners in several ways. First, it advances the research on e-commerce adoption by incorporating and analyzing drivers at multiple levels in a single model. This method is robust as it allows for a cross-country analysis while controlling for confounding effects of other individual and macro factors. Second, this study observes and further examines the role of national culture toward the application of e-commerce, thus complementing existing studies that have focused extensively on formal institutions such as telecommunication infrastructure. Third, this research is among the very few studies that specifically looks at a particular economic bloc. This approach is particularly vital for upholding the common aspirations of ASEAN in fully leveraging the benefits of the digital economy while some citizens and member states are still impeded by personal and cultural barriers.

\section{E-commerce as a strategic measure of the ASEAN economic community (AEC)}

ASEAN was established on 8 August 1967 in Bangkok, Thailand, and currently consists of ten countries: Brunei, Cambodia, Indonesia, Laos, Malaysia, Myanmar, the Philippines, Singapore, Thailand, and Vietnam. There are seven goals of this regional bloc, including the acceleration of economic growth, social progress, and cultural development in order to strengthen the foundation for a prosperous and peaceful community, through active collaboration and mutual assistance among the members.

AEC is one of three pillars comprising the ASEAN community vision. In particular, AEC Blueprint 2025 provides a broader strategic roadmap toward a highly competitive and innovative region focusing on five key areas, particularly the enhancement of connectivity and sectoral cooperation within the economic bloc. To achieve that, several measures have been planned including the advancement of e-commerce adoption among both businesses and citizens of ASEAN.

Acknowledging the potential contributions of e-commerce, ASEAN initiated the e-ASEAN Framework Agreement 2000 for promoting the adoption and usage of e-based business platforms and digital technology to enhance the competitiveness of the bloc. However, these efforts are hindered by the socio-economic heterogeneity among the ten member countries. The differences are observed not only in terms of economic development, but also in cultural attributes. This issue has been seriously addressed in the Initiative for ASEAN Integration and the ASEAN Equitability Development Monitor 2014 that emphasize the need to narrow the development gap, particularly in countries like Cambodia, Laos, Myanmar, and Vietnam. As such, the prevalence of e-commerce varies across all ASEAN members.

\section{E-commerce individual-influencer: demographic characteristics \\ Age}

Age simply measures one's date of birth, yet strongly defines the specific behavior of people at different life stages. Psychologically, idiosyncrasies in the purchasing behavior of consumers are influenced by the physical and cognitive aging processes, as well as accumulated life experiences [53]. Each generational cohort varies by attitudes, preferences and values, which eventually shape buying patterns including preferred methods for shopping and buying $[45,46]$. Accordingly, empirical evidence supports age as a significant factor in explaining an individual's decision regarding the adoption of e-commerce $[13,37,63]$.

Although most studies found that young consumers are the dominant users of e-commerce, in some countries like Israel [37] and Taiwan [63], a different pattern emerges. Yet, while older consumers today are using the internet more often than before, the younger generation has comparatively more active users making online purchases $[25,55]$. 
Young people, especially those born after 2000, are considered the first high-tech generation [42]. They are more computer-literate and exposed to cutting-edge technological applications. Also, young consumers are very consumption-oriented and sophisticated when shopping [32]. They do not simply consider shopping as an act of buying things, but rather a decision that has to be made based on an evaluation of a set of information $[18,37]$. Thus, many of them choose to adopt e-commerce because the information provided by the internet is broader and richer than what could be acquired in the physical stores.

On the other hand, older people prefer a traditional way of seeking information before proceeding with a purchase [24]. They still want to hear an explanation about the product or service from the salesperson rather than relying on a description displayed on the internet [26]. In fact, older consumers are not bothered by the limited information available in the store because they are considered experienced shoppers that are capable of making buying decisions with less knowledge about the products [10]. Lastly, older people resist using e-commerce because they have stronger risk avoidance tendencies than younger consumers [48].

Hypothesis 1: E-commerce usage is more prevalent among younger customers.

\section{Gender}

Another important demographic factor that explains willingness to perform online purchases is gender. Indeed, men and women across cultures and nationalities have different thoughts on the adoption of e-commerce $[55,60]$. Accordingly, empirical studies found that gender can distinguish several aspects of computer applications including e-commerce, such as level of acceptance $[23,25]$, perceived risk [19], and types of product purchased [52]. Yet, research has not yet reached a solid finding on whether men or women are more likely to do online shopping $[9,66]$. The principle barrier that inhibits the effort is that most studies do not control for other related variables such as education and income level of the respondents. Thus, in a study where men are found to be more active users, it might not be because of gender, but because of their high income level, as men often earn more than women.

This research, though, predicts that gender plays a significant role in explaining e-commerce behavior, even after controlling for the confounding variables of employment status, education, and income level. In brief, we follow the argument of Zhou et al. [66] that the psycho-socio traits of men and women lie at different edges, thus shaping their attitudes toward online shopping. Females and males have different attitudinal and behavioral orientations that, while comprised in their genetic makeup, are more importantly derived from their social experiences [49]. First, the purchasing behavior of women is largely driven by emotional and social interaction, while men opt for convenience. Hence, e-commerce is rather less attractive for women due to the absence of direct interaction with the sellers [15]. Second, the types of products sold on the internet are more suitable for men than women [52, 60]. Men are associated with "hard" products like computers, electronic gadgets, and sport apparel which are widely available. "Soft" products such as food and textiles for women are not only limited but also require actual testing prior to purchase. In the same vein, women, more than men, appreciate the physical evaluation of products including seeing, touching, and feeling the product in order to make a purchasing decision $[11,15]$. This is another reason why many women found e-commerce to be less accommodating than conventional shopping. Lastly, since e-commerce activities are plagued by concerns of privacy and security [7], the platform is less favorable for women, who avoid risk [19], than men who easily trust people [60].

In short, in agreement with the majority of studies, we expect men to be more likely to adopt e-commerce than women $[35,61,63]$.

Hypothesis 2: E-commerce usage is more prevalent among men.

\section{Education}

Classic beliefs contend that education is an essential quality that molds a person's value systems, cognitive preferences, learning capabilities, skills, and innovativeness [5]. Accordingly, one's level of education can predict if they will be proactive or reactive toward cutting-edge technological applications in daily life [4]. In general, people with a higher education demonstrate greater knowledge, experience, and risk tolerance, making them eager to adopt online shopping [6,34]. Previous research supports the argument that a higher level of education has a positive effect on a person's tendency to use an e-commerce platform at both the individual$[3,20,57,58]$ and firm-level $[12,17]$.

Hypothesis 3: E-commerce usage is more prevalent among customers with a higher education level. 


\section{Employment status and income level}

Since education, employment status, and income level are positively related, some studies ascertain that a person's employment status is a significant factor in explaining e-commerce adoption. For example, Pérez-Hernández and Sánchez-Mangas [47] found that the probability of making an online purchase is higher among workers than unemployed individuals. Perhaps a better explanation is that people with a job earn money that enables them to buy things online. Thus, the following examination shall explore the relationship between income level and probability of online shopping.

Indeed, even before online shopping was well established, studies discovered that at-home shoppers are among higher income earners [14]. Subsequently, empirical studies support similar findings that online shoppers possess more wealth than shoppers at traditional stores $[3,38,57,58]$. There are two possible reasons for this. First, wealthier people are more convenience-oriented, risk tolerant, and less brand and price conscious [16], all of which are consistent with e-commerce adoption. Second, most items sold over the internet like books, computer hardware, etc., are considered "normal goods," those for which demand increases as income increases [66]. Thus, we posit the following:

Hypothesis 4: E-commerce usage is more prevalent among working customers.

Hypothesis 5: E-commerce usage is more prevalent among customers with a higher income level.

\section{E-commerce country-influencer: national culture}

While most studies have emphasized the importance of formal institutions on the diffusion of e-commerce, they often neglect the underlying effect of socio-cultural norms and values [2]. Culture has long been recognized as a vital factor that influences consumer behavior, including preference to adopt e-commerce [67]. In brief, culture can be defined as the characteristics of a human group that shares basic assumptions on correct ways to perceive, think, and feel [51]. Although national culture is a macro-level phenomenon, the effect is reasonably observable at the individual level [54]. Thus, examining the country's culture for consumers is both appropriate and meaningful for explaining individual behavior [31], as demonstrated in other research (e.g., [22]).

One of the most prominent dimensions of national culture is described by Hofstede [27]. He defines national culture as a set of assumptions, attitudes, behaviors, beliefs, expectations, and values, shared by a group of people, called "the collective programming of the mind" distinguishing members of one group from another. Although the time orientation dimension (long-term versus short-term) and the happiness dimension (indulgence versus restraint) have been added in later time, this research opts to focus on the four original dimensions: power distance, individualism versus collectivism, masculinity versus femininity, and uncertainty avoidance.

\section{Power distance}

The power distance dimension generally measures the degree to which a society accepts inequality in distribution of power [28]. In practice, high power distance societies accept the establishment of hierarchical order with no justifications required. On the other hand, low power distance societies enjoy equality, egalitarianism, and neutrality that removes the barriers between superiors and subordinates. In other words, there is stronger interaction between the two parties in the latter than in the former, further spurring trust value among the members [65]. Yet, this trust value is a pre-condition for the adoption of e-commerce because of the great uncertainty inherent to online shopping, e.g., faceless transactions, virtual payment, etc. [2]. In contrast, the trust deficit in a high power distance society tends to create a prejudiced attitude toward other people on the internet, such as sellers are dishonest and unethical, which impedes the interest to use e-commerce [65].

Hypothesis 6: E-commerce usage is more prevalent among customers in counties with low power distance.

\section{Individualism}

The portrayed self-image dimension defines the number of social contacts that a person feels responsible for taking care of, either oneself and immediate family (individualism) or extended relatives and other ingroup members of the society (collectivism) [28]. The theoretical approach to understanding the relationship between individualism and collectivism and online shopping behavior emphasizes the emergence of trust value in the society [2]. Although trust value is considered to be stronger in a collectivist society, it is restricted to ingroup members only [30]. In order words, this type of society does not trust new, strange, or unusual things [59]. Therefore, resistance to change is perceivably higher among customers in collectivist nations, causing the acceptance of new technology to be relatively slower [2]. On the other hand, individualistic countries uphold the principle of universalism, where the citizens identify themselves within broader groups of society. These people are also good at meeting new members and generally more willing to trust them [64]. Applying this 
understanding into the context of technology acceptance, we propose that the propensity to use e-commerce is higher among customers in individualistic countries.

Hypothesis 7: E-commerce usage is more prevalent among customers in high individualism countries.

\section{Masculinity}

Masculinity and femininity describe social gender roles that either emphasize achievement, heroism, assertiveness, and material rewards for success ("tough"-related values in the former) or appreciate cooperation, modesty, and caring ("tender"-related values in the latter) [28]. In fact, Hofstede [27] found that people in high masculinity societies consider most people to be untrustworthy. Instead, high femininity societies easily embrace harmonious relationships with other people. Srite and Karahanna [54] posit that e-commerce provides a medium for shopping which is more convenient and pleasant than traditional stores, thus is likely preferred by people in a high femininity society.

Hypothesis 8: E-commerce usage is more prevalent among customers in low masculinity countries.

\section{Uncertainty avoidance}

Uncertainty avoidance (UA) describes the extent to which a society feels threatened by, as opposed to tolerant of, uncertainty and ambiguity [28]. In practice, people in low UA nations are more willing to accept risks when trying new things, thus are more likely to venture into entrepreneurship and adopt modern technologies [21].
On the other hand, high UA societies are comfortable with the status-quo and are resistant to change, thus act conservatively [56]. As a consequence, they are slower in embracing modern technology [64].

Another reason to suspect that low UA countries are more likely to adopt e-commerce is that trust value is high among the citizens [31]. Since these people are open to accept change although it is potentially risky, they are actually ready to build trust over those uncertainties. Similarly, as a new form of trade, e-commerce is still considered more uncertain than traditional stores, and only customers with strong trust value are willing to use it. In contrast, members of high UA cultures would simply ignore the existence of this new technology [8].

Hypothesis 9: E-commerce usage is more prevalent among customers in low uncertainty avoidance countries.

The framework of this research is presented in Fig. 1.

\section{Methods and data}

To test the hypotheses, we utilize individual-level data from the World Bank Global FINDEX database 2017. FINDEX is the world's most complete dataset on financial inclusion around the globe, sponsored by the Bill and Melinda Gates Foundation.

In 2017, FINDEX collected data from a survey to over 150,000 national representatives in more than 140 countries. Although FINDEX 2017 covers 10,206 individuals in nine ASEAN countries (except Brunei), data on Hofstede's national culture only includes six countries for analysis: Indonesia, Malaysia, Philippine, Singapore, Thailand, and Vietnam. After integrating data from both sources, including that of the World Bank as a control,

\begin{tabular}{|l|}
\hline Individual demographics \\
1) Age $(H 1)$ \\
2) Gender $(H 2)$ \\
3) Education $(H 3)$ \\
4) Employment status $(H 4)$ \\
5) Income (H5) \\
\hline \hline National culture \\
1) Power distance $(H 6)$ \\
2) Individualism $(H 7)$ \\
3) Masculinity $(H 8)$ \\
4) Uncertainty avoidance $(H 9)$
\end{tabular}

Fig. 1 Framework of study

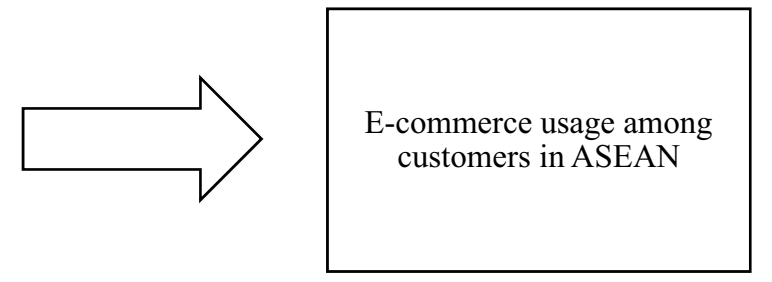


and omitting incomplete entries, the final observations for analysis consist of 5870 individuals from those six countries.

\section{Dependent variable}

E-commerce adoption behavior of individual is measured in binary: if respondent has, or has not, personally bought things online in the past 12 months. This is a more accurate measure of e-commerce usage because prior to the 2017 data, FINDEX asked if respondents “... made payments on bills or bought things online using the Internet," where the use of the internet is ambiguous on the purposes other than shopping.

\section{Explanatory variables}

As mentioned, this study hypothesizes on both individual demographic characteristics and country-level culture. The former draws on FINDEX while the latter utilizes Hofstede's national culture publicly accessible on the website. Details on each variable are presented in Table 1.

While age is measured continuously, gender and employment status are dichotomous, and education and income level are ordinal-type. All dimensions of national culture are scored from 0 to 100 to describe the degree between individualism versus collectivism, masculinity versus femininity, etc.

\section{Control variables}

In order to improve robustness of the model, we include individual and country confounding variables: account ownership and economic status of a country.

First, the eventual e-purchase behavior is largely determined by the ownership of a means to make online payments [44]. The business-to-customer e-commerce index developed by the United Nations Conference on Trade and Development also acknowledges that the demand for e-commerce is justified when a person has an account at a bank or another type of financial institution, or mobile money account.

Second, we control for a country's common economic development: gross domestic product (GDP) per capita. Since there are only six countries for analysis, we are unable to include more country controls because most of them are strongly correlated, potentially causing multicollinearity. For example, GDP per capita is correlated with an internet penetration rate of 0.794, Global Cybersecurity Index at 0.850 , and population size at -0.911 .

The correlations among the variables are shown in Table 2.

\section{Descriptive analysis}

Unlike advanced regional economic blocs such as the European Union, ASEAN integration is rather less extensive; most terms are confined to free trade agreements. The principle barrier to greater integration is the wide gaps between countries with regards to political ideology, economic development, as well as socio-cultural values,

Table 1 Definitions of variables

\begin{tabular}{|c|c|c|}
\hline Variable & Definition & Source \\
\hline \multicolumn{3}{|l|}{ Dependent variable } \\
\hline E-commerce adoption & $\begin{array}{l}\text { Dummy, equal to } 1 \\
\text { If respondents have personally bought things online using the Internet in the past } 12 \text { months }\end{array}$ & FINDEX \\
\hline \multicolumn{3}{|l|}{ Individual demographics } \\
\hline Age & Age of respondents & FINDEX \\
\hline Gender & Dummy, equal to 1 if respondent is male & FINDEX \\
\hline Education & Range 1 to 3: primary, secondary and tertiary & FINDEX \\
\hline Employment status & Dummy, equal to 1 if respondent is currently employed & FINDEX \\
\hline Income level & Range 1 to 5: poorest to richest & FINDEX \\
\hline \multicolumn{3}{|l|}{ National culture } \\
\hline Power distance & Degree to which the less powerful members of a society accept and expect that power is distributed unequally & Hofstede \\
\hline Individualism & Degree to which individuals are expected to take care of only themselves and their immediate families & Hofstede \\
\hline Masculinity & Degree to which societies prefer achievement, heroism, assertiveness, and material rewards for success & Hofstede \\
\hline Uncertainty avoidance & Degree to which the members of a society feel uncomfortable with uncertainty and ambiguity & Hofstede \\
\hline \multicolumn{3}{|l|}{ Controls } \\
\hline Account ownership & $\begin{array}{l}\text { Dummy, equals to } 1 \\
\text { If respondents have an account at a bank or another type of financial institution, or mobile money account }\end{array}$ & FINDEX \\
\hline GDP per capita & Gross domestic product divided by midyear population & World Bank \\
\hline
\end{tabular}


Table 2 Descriptive statistic and correlations

\begin{tabular}{|c|c|c|c|c|c|c|c|c|c|c|c|c|c|c|c|}
\hline & & Mean & SD & 1 & 2 & 3 & 4 & 5 & 6 & 7 & 8 & 9 & 10 & 11 & 12 \\
\hline 1 & Age & 42.31 & 16.82 & 1.00 & & & & & & & & & & & \\
\hline 2 & Gender & 0.43 & 0.50 & -0.02 & 1.00 & & & & & & & & & & \\
\hline 3 & Education & 1.86 & 0.67 & -0.35 & 0.08 & 1.00 & & & & & & & & & \\
\hline 4 & Employment status & 0.70 & 0.46 & -0.12 & 0.16 & 0.15 & 1.00 & & & & & & & & \\
\hline 5 & Income level & 3.10 & 1.43 & -0.11 & 0.03 & 0.29 & 0.13 & 1.00 & & & & & & & \\
\hline 6 & Power distance & 79.80 & 12.74 & -0.21 & 0.08 & 0.27 & -0.03 & 0.01 & 1.00 & & & & & & \\
\hline 7 & Individualism & 21.96 & 5.69 & -0.05 & 0.05 & 0.14 & -0.01 & -0.01 & 0.69 & 1.00 & & & & & \\
\hline 8 & Masculinity & 47.01 & 9.35 & -0.14 & 0.04 & 0.17 & -0.06 & 0.01 & 0.70 & 0.72 & 1.00 & & & & \\
\hline 9 & Uncertainty avoidance & 38.36 & 17.34 & 0.00 & -0.04 & -0.27 & 0.00 & 0.02 & -0.10 & -0.01 & -0.23 & 1.00 & & & \\
\hline 10 & E-commerce & 0.23 & 0.42 & -0.27 & 0.01 & 0.40 & 0.15 & 0.20 & 0.05 & -0.01 & 0.00 & -0.30 & 1.00 & & \\
\hline 11 & Account ownership & 0.65 & 0.48 & 0.00 & 0.01 & 0.28 & 0.12 & 0.15 & -0.03 & -0.09 & -0.14 & -0.13 & 0.30 & 1.00 & \\
\hline 12 & GDP per capita (log) & 3.83 & 0.47 & 0.11 & 0.02 & 0.19 & 0.01 & -0.04 & -0.07 & -0.12 & -0.04 & -0.62 & 0.32 & 0.47 & 1.00 \\
\hline
\end{tabular}

Significant at the $p<0.0310$ level when Pearson correlations $>0.04$ and $<-0.03$

among others. According to the World Bank classification, of the six countries studied, Singapore is the only high-income nation, followed by Malaysia and Thailand as upper-middle income countries, while Indonesia, the Philippines, and Vietnam are grouped as lower-middle economies.

In a same vein, the national culture for these countries is also varied, particularly for the dimensions of power distance and uncertainty avoidance. For instance, Malaysia has the highest power distance not only in the region, but also in the world (100) while Thailand has the narrowest in ASEAN (64). Also, Thailand is the most risk averse with an uncertainty avoidance measure of 64 , while Singapore is extremely risk tolerant (8).

In sum, heterogeneity across member states provides a unique context for researching how individual characteristics interact with informal institutions to influence the online purchasing behavior of customers.

Graphical representation of the national culture is displayed in Fig. 2.

\section{Results and discussion}

Before running the model, we took adequate measures to ensure the absence of common method bias (although this is less likely because our dataset is compiled from multiple sources), multicollinearity using variance inflation factors, and outliers. The final dataset is, therefore, robust for analysis.

To test the hypotheses, we employ ordinary least squares (OLS) regression for estimating the relationship between explanatory variables and the online purchasing behavior of customers. Table 3 presents the regression results. Model 1 includes only the control variables. Model 2 tests individual demographic variables, while Model 3 runs on all dimensions of

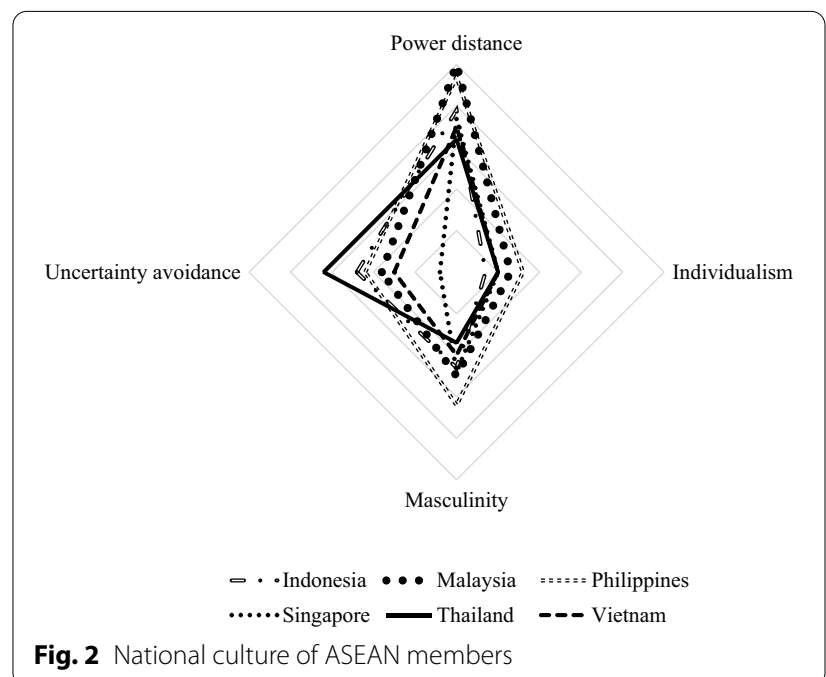

national culture. Model 4 combines both individual and country-level variables and runs a full model. Overall, the adjusted $R^{2}$ improved significantly by $17.1 \%$ from Model 1 to Model 4.

For individual predictors, Model 2 and 4 consistently support hypothesis 1, 3, 4 and 5 that e-commerce is more prevalent among customers who are younger, have a higher level of education, are currently employed, and have a higher salary. However, hypothesis 2 is not supported because female customers are found more active online shoppers than men. Although the findings contradict our initial expectations, it is not totally surprising because some earlier research has found similar results, and there are both theoretical and methodological reasons to support the findings. First, although men have long been recognized as active 
Table 3 Regression results

\begin{tabular}{|c|c|c|c|c|}
\hline & Model 1 & Model 2 & Model 3 & Model 4 \\
\hline \multicolumn{5}{|c|}{ Individual characteristics } \\
\hline Age & & $\begin{array}{l}-0.005^{* * *} \\
(0.000)\end{array}$ & & $\begin{array}{l}-0.005^{* * *} \\
(0.000)\end{array}$ \\
\hline Gender & & $\begin{array}{l}-0.030^{* *} \\
(0.009)\end{array}$ & & $\begin{array}{l}-0.031^{* *} \\
(0.009)\end{array}$ \\
\hline Education & & $\begin{array}{l}0.138^{* * *} \\
(0.008)\end{array}$ & & $\begin{array}{l}0.122^{* * *} \\
(0.008)\end{array}$ \\
\hline Employment status & & $\begin{array}{l}0.068^{* * *} \\
(0.010)\end{array}$ & & $\begin{array}{l}0.061^{* * *} \\
(0.010)\end{array}$ \\
\hline Income & & $\begin{array}{l}0.030^{* * *} \\
(0.003)\end{array}$ & & $\begin{array}{l}0.031^{* * *} \\
(0.003)\end{array}$ \\
\hline \multicolumn{5}{|l|}{ National culture } \\
\hline Power distance & & & $\begin{array}{l}0.005^{* * *} \\
(0.001)\end{array}$ & $\begin{array}{l}0.001 \\
(0.001)\end{array}$ \\
\hline Individualism & & & $\begin{array}{l}0.004^{* *} \\
(0.001)\end{array}$ & $\begin{array}{l}0.006^{* * *} \\
(0.001)\end{array}$ \\
\hline Masculinity & & & $\begin{array}{l}-0.008^{* * *} \\
(0.001)\end{array}$ & $\begin{array}{l}-0.007^{* * *} \\
(0.001)\end{array}$ \\
\hline $\begin{array}{l}\text { Uncertainty avoid- } \\
\text { ance }\end{array}$ & & & $\begin{array}{l}-0.006^{* * *} \\
(0.000)\end{array}$ & $\begin{array}{l}-0.004^{* * *} \\
(0.000)\end{array}$ \\
\hline \multicolumn{5}{|l|}{ Controls } \\
\hline Account ownership & $\begin{array}{l}0.163^{* * *} \\
(0.012)\end{array}$ & $\begin{array}{l}0.074^{* * *} \\
(0.011)\end{array}$ & $\begin{array}{l}0.183^{* * *} \\
(0.012)\end{array}$ & $\begin{array}{l}0.090^{* * *} \\
(0.012)\end{array}$ \\
\hline GDP per capita (log) & $\begin{array}{l}0.212^{* * *} \\
(0.012)\end{array}$ & $\begin{array}{l}0.241^{* * *} \\
(0.011)\end{array}$ & $\begin{array}{l}0.070^{* * *} \\
(0.016)\end{array}$ & $\begin{array}{l}0.152^{* * *} \\
(0.015)\end{array}$ \\
\hline Constant & $\begin{array}{l}-0.693^{* * *} \\
(0.044)\end{array}$ & $\begin{array}{l}-0.916^{* * *} \\
(0.045)\end{array}$ & $\begin{array}{r}-0.014 \\
(0.081)\end{array}$ & $\begin{array}{l}-0.254^{* *} \\
(0.079)\end{array}$ \\
\hline$R^{2}$ & 0.132 & 0.287 & 0.170 & 0.303 \\
\hline Adjusted $R^{2}$ & 0.131 & 0.286 & 0.169 & 0.302 \\
\hline Fvalue & $444.997^{* * *}$ & $337.637^{* * *}$ & $200.452^{* * *}$ & $231.408^{* * *}$ \\
\hline
\end{tabular}

${ }^{* * *} p<0.001,{ }^{* *} p<0.010,{ }^{*} p<0.050$

users of technology breakthroughs, recent trends show more women embracing online applications including e-commerce platforms [25]. In certain contexts, e-commerce adoption among women has exceeded male shoppers [55]. In fact, global retailers now consider women to be one of the fastest growing segments to be exploited in online shopping platforms [60]. Second, low e-commerce usage among men in this study could not entirely attributed to the gender-related physiological characters because e-commerce behavior is also largely explained by the social experiences [49]. Since our model does not control for prior social experience, we could argue that more male customers reluctant to do online purchase probably because his close relatives and friends had bad experiences with the online platform, i.e., fraud or technical errors causing double charged, etc.

In terms of the national culture, models 3 and 4 confirm hypotheses 7, 8 and 9 that countries with strong individualism, low masculinity, and low uncertainty avoidance exhibit higher rates of e-commerce adoption among the citizens. However, no support is received for hypothesis 6 . Our results suggest that power distance does not explain the discrepancy in e-commerce diffusion between ASEAN countries. Although prior research argued that power distance dimension does explain the level of trust in the society [65], the effect on eventual e-commerce behavior is not apparent, presumably because the interactions in an online platform are virtual. Therefore, power gaps between parties are less visible in electronic interpersonal communication regardless the power distance of the society.

Lastly, for control variables, the results show that account ownership and a country's GDP are significant and positively related with e-commerce adoption.

Table 4 displays the profile of e-commerce users in ASEAN following the results of this study.

\section{Conclusions}

As an economic bloc, can ASEAN ensure that strategic plans for promoting e-commerce platforms in the AEC Blueprint 2025 are equally beneficial to all country members? Do demographic characteristics interact with national culture to influence the eventual online shopping behavior of customers? We attempt to answer these issues by arguing that e-commerce adoption is explained by the integration of both levels of factors: individual

Table 4 Profile of e-commerce users in ASEAN

\begin{tabular}{llll}
\hline & Who are they? & Where they live? \\
\hline Individual demographics & & National culture & - \\
Age & Young & Power distance & High \\
Gender & Female & Individualism & Low \\
Education & High & Masculinity & Low \\
Employment status & Yes & Uncertainty avoidance & \\
Income & High & GDP per capita & High \\
Account ownership & Yes & & \\
\hline
\end{tabular}


traits and country features. More importantly, we posit that national culture plays as important a role as formal institutions to predict the prevalence of e-commerce adoption among citizens in a country. Thus, the quest to identify online shopping trends requires not only exploring who the customer is, but also where they live.

Our empirical approach draws on multiple sources of data to test the relationship among individual characteristics (age, gender, education, employment, and income) and national culture (power distance, individualism, masculinity, and uncertainty avoidance) to the propensity for online shopping among 5870 individuals in six ASEAN countries. The results of this research highlight on important contributions for academic and practical purposes.

First, the profile of e-commerce users in ASEAN is rather homogenous in terms of the demographics. Online shopping platforms are found to be used mostly by customers that are female, young, have a higher education level, are currently employed and earn more income. This research provides evidence that although one of the core missions of AEC 2025 is to ensure all citizens in the region benefit from the advantageous offered in e-commerce, the eventual adoption remains a privilege for young individuals with better education and higher salaries. Implicitly, e-commerce is prevalent only among those who have the access and ability to exploit the technology, and more importantly, could afford to pay.

Second, this study establishes a conceptual link between two important yet isolated research themes: e-commerce behavior and institutions. Specifically, we shed light on the fact that that national culture is as important as formal institutions in pushing customers into adopting e-commerce. From that, we propose that policies designed to encourage individuals to use the internet for shopping should not only focus on formal institutions such as infrastructure and regulation, but also on cultivating favorable socio-values related to virtual business activities such as trust. This suggests that tangible aspects are less important; our controls show a strong evidence that prosperous economic status is extremely vital as it helps the country to provide better internet coverage and speed, as well as strong financial institutions for account ownership.

In sum up, policy makers, particularly in ASEAN member countries, should acknowledge that e-commerce platforms are still not fully exploited by all, but instead by a rather specific type of customer: younger, more educated, and wealthier. To a certain extent, this profile sends a signal that the trend only favors people in more developed countries where the education system is better and disposable income is higher. This should be an alarming call for ASEAN committees to continuously and aggressively narrow the development gaps across the country members. Lastly, the initiatives at the macro-level to promote e-commerce adoption should not neglect the important aspect of socio-cultural values. Although national culture is not visibly changed in the short or medium term, local government should strive to nurture favorable values in society such as trust and risk tolerance.

Despite its contributions, this research should be viewed in light of several limitations, thus suggestions for future research. First, data of this research only covers six ASEAN countries. Even if it tested all ten members, it is still considered fewer in comparison to other larger regional blocs such as the 54 members of the African Union, 28 members of the EU, and 22 countries in the Arab League. This limitation concerns the generalizability of our findings particularly as it inhibits us from inserting more country-level controls. Second, our dataset relies solely on secondary data that did not capture the personalities of individuals. Although our theoretical argument has partly based on the relationship between demographic factors and the personalities of individuals, this study does not directly test that to further examine the effect on online purchase behavior. Lastly, this research does not demonstrate causality. Rather, we hold to a strong assumption that individual behavior is determined by both personal and social environment, not vice versa. In other words, it is theoretically sound to argue that a customer's age determines his or her online purchase behavior, but it is extremely difficult to comprehend that shopping online can make someone attain a higher level of education.

\section{Abbreviations}

ASEAN: Association of Southeast Asia Nations; AEC: ASEAN Economic Community; GDP: gross domestic product; IA: uncertainty avoidance; OECD: Organisation for Economic Co-operation and Development; OLS: ordinary least squares.

\section{Acknowledgements}

Not Applicable.

\section{Authors' contributions}

The author read and approved the final manuscript.

Funding

This research was funded by the National University of Malaysia, under Grant DCP-2017-017/3.

\section{Availability of data and materials}

The datasets analyzed during the current study are available in the World Bank Global FINDEX, https://globalfindex.worldbank.org/ and Hofstede's Insight, https://www.hofstede-insights.com/product/compare-countries/ [29, 62].

\section{Competing interests}

The author declares that he has no competing interests. 
Received: 15 April 2020 Accepted: 21 December 2020

Published: 12 January 2021

\section{References}

1. Agarwal J, WuT (2015) Factors influencing growth potential of E-commerce in emerging economies: an institution-based N-OLI framework and research propositions. Thunderbird Int Bus Rev 57(3):197-215

2. Agarwal J, Wu T (2018) E-commerce in emerging economies: A multitheoretical and multilevel framework and global firm strategies. In: Agarwal J, Wu T (eds) Emerging issues in global marketing. Springer, Berlin, pp 231-253

3. Allred CR, Smith SM, Swinyard WR (2006) E-shopping lovers and fearful conservatives: a market segmentation analysis. Int J Retail Distrib Manag 34(4/5):308-333

4. Awa HO, Baridam DM, Nwibere BM (2015) Demographic determinants of electronic commerce (EC) adoption by SMEs: a twist by location factors. J Enterprise Inf Manag 28(3):326-345

5. Becker MH (1970) Sociometric location and innovativeness: reformulation and extension of the diffusion model. Am Sociol Rev 35:267-282

6. Bhatnagar A, Misra S, Rao HR (2000) On risk, convenience, and internet shopping behavior. Commun ACM 43(11):98

7. Boritz JE, No WG (2011) E-commerce and privacy: exploring what we know and opportunities for future discovery. J Inf Syst 25(2):11-45

8. Chai L, Pavlou PA (2004) From "ancient" to "modern": a cross-cultural investigation of electronic commerce adoption in Greece and the United States. J Enterprise Inf Manag 17(6):416-423

9. Chang MK, Cheung W, Lai VS (2005) Literature derived reference models for the adoption of online shopping. Inf Manag 42(4):543-559

10. Cheung CM, Xiao BS, Liu IL (2014) Do actions speak louder than voices? The signaling role of social information cues in influencing consumer purchase decisions. Decis Support Syst 65:50-58

11. Cho J (2004) Likelihood to abort an online transaction: influences from cognitive evaluations, attitudes, and behavioral variables. Inf Manag 41(7):827-838

12. Chuang TT, Nakatani K, Zhou D (2009) An exploratory study of the extent of information technology adoption in SMEs: an application of upper echelon theory. J Enterprise Inf Manag 22(1/2):183-196

13. Cole C, Laurent G, Drolet A, Ebert J, Gutchess A, Lambert-Pandraud R, Mullet E, Norton MI, Peters E (2008) Decision making and brand choice by older consumers. Mark Lett 19(3-4):355-365

14. Darian JC (1987) In-home shopping: are there consumer segments? J Retail 40:81-88

15. Dittmar H, Long K, Meek R (2004) Buying on the internet: gender differences in on-line and conventional buying motivations. Sex Roles 50(5-6):423-444

16. Donthu N, Garcia A (1999) The internet shopper. J Advert Res 39(3):52

17. Federici T (2009) Factors influencing ERP outcomes in SMEs: a post-introduction assessment. J Enterprise Inf Manag 22(1/2):81-98

18. Ganesan-Lim C, Russell-Bennett R, Dagger T (2008) The impact of service contact type and demographic characteristics on service quality perceptions. J Serv Mark 22(7):550-561

19. Garbarino E, Strahilevitz M (2004) Gender differences in the perceived risk of buying online and the effects of receiving a site recommendation. J Bus Res 57(7):768-775

20. Goldfarb A, Prince J (2008) Internet adoption and usage patterns are different: implications for the digital divide. Inf Econ Policy 20(1):2-15

21. Gong W (2009) National culture and global diffusion of business-toconsumer e-commerce. Cross Cult Manag Int J 16(1):83-101

22. Hallikainen $\mathrm{H}$, Laukkanen $\mathrm{T}$ (2018) National culture and consumer trust in e-commerce. Int J Inf Manag 38(1):97-106

23. Hasan B (2010) Exploring gender differences in online shopping attitude. Comput in Hum Behav 26(4):597-601

24. Heaney JG (2007) Generations X and Y's internet banking usage in Australia. J Financial Serv Mark 11(3):196-210

25. Hernández B, Jiménez J, José Martín M (2011) Age, gender and income: do they really moderate online shopping behaviour? Online Inf Rev 35(1):113-133

26. Himmel B (2008) Different strokes for different generations. Rental Product News 30(7):42-46
27. Hofstede G (1980) Culture's consequences international differences in work-related values. Beverly Hills, CA Sage

28. Hofstede G (2001) Culture's consequences: comparing values, behaviors, institutions and organizations across nations, 2nd edn. Sage Publication, Thousand Oaks

29. Hofstede's Insight. https://www.hofstede-insights.com/product/compa re-countries/. Accessed 1 June 2019

30. Huff L, Kelley $L$ (2003) Levels of organizational trust in individualist versus collectivist societies: a seven-nation study. Organ Sci 14(1):81-90

31. Hwang Y, Lee KC (2012) Investigating the moderating role of uncertainty avoidance cultural values on multidimensional online trust. Inf Manag 49(3-4):171-176

32. Jackson V, Stoel L, Brantley A (2011) Mall attributes and shopping value: differences by gender and generational cohort. J Retail Consum Serv 18(1):1-9

33. Kwak J, Zhang Y, Yu J (2019) Legitimacy building and e-commerce platform development in China: the experience of Alibaba. Technol Forecast Soc Change 139:115-124

34. Li H, Kuo C, Rusell MG (1999) The impact of perceived channel utilities, shopping orientations, and demographics on the consumer's online buying behavior. J Comput Med Commun 5(2):JMC521

35. Lian JW, Yen DC (2014) Online shopping drivers and barriers for older adults: age and gender differences. Comput Hum Behav 37:133-143

36. Lim YM, Cham TH (2015) A profile of the Internet shoppers: evidence from nine countries. Telemat Inform 32(2):344-354

37. Lissitsa S, Kol O (2016) Generation X vs. Generation Y-A decade of online shopping. J Retail Consum Serv 31:304-312

38. Mahmood MA, Bagchi K, Ford TC (2004) On-line shopping behavior: cross-country empirical research. Int J Electron Commerce 9(1):9-30

39. Martinez CA, Williams C (2010) National institutions, entrepreneurship and global ict adoption: a cross-country test of competing theories. $J$ Electron Commerce Res 11(1):73-91

40. Martinsons MG (2008) Relationship-based e-commerce: theory and evidence from China. Inf Syst J 18(4):331-356

41. Mubarak Alharbi I, Zyngier S, Hodkinson C (2013) Privacy by design and customers' perceived privacy and security concerns in the success of e-commerce. J Enterprise Inf Manag 26(6):702-718

42. Norum PS (2003) Examination of generational differences in household apparel expenditures. Fam Consum Sci Res J 32(1):52-75

43. OECD. Publishing, \& Organisation for Economic Co-operation and Development (2011) OECD guide to measuring the information society 2011 Organisation for Economic Co-operation and Development

44. Oxley JE, Yeung B (2001) E-commerce readiness: institutional environment and international competitiveness. J Int Bus Stud 32(4):705-723

45. Parment A (2011) Generation Y in consumer and labour markets. Routledge, Abingdon

46. Parment A (2013) Generation Y vs. Baby Boomers: shopping behavior, buyer involvement and implications for retailing. J Retail Consum Serv 20(2):189-199

47. Pérez-Hernández J, Sánchez-Mangas R (2011) To have or not to have Internet at home: implications for online shopping. Inf Econ Policy 23(3-4):213-226

48. Reisenwitz TH, lyer $R$ (2009) Differences in generation $x$ and generation $y$ : implications for the organization and marketers. Mark Manag $J$ 19(2):91-103

49. San Martín S, Jiménez NH (2011) Online buying perceptions in Spain: can gender make a difference? Electron Mark 21(4):267-281

50. San Martín S, Camarero C, San José R (2011) Dual effect of perceived risk on cross-national e-commerce. Internet Res 21(1):46-66

51. Schein EH (1991) What is culture. Sage, Newbury Park

52. Sebastianelli R, Tamimi N, Rajan M (2008) Perceived quality of online shopping: does gender make a difference? J Internet Commerce 7(4):445-469

53. Sharma P, Chen IS, Luk ST (2012) Gender and age as moderators in the service evaluation process. J Serv Mark 26(2):102-114

54. Srite M, Karahanna E (2006) The role of espoused national cultural values in technology acceptance. MIS Q 30:679-704

55. Stafford TF, Turan A, Raisinghani MS (2004) International and cross-cultural influences on online shopping behavior. J Glob Inf Technol Manag 7(2):70-87 
56. Steenkamp JBE, Ter Hofstede F, Wedel M (1999) A cross-national investigation into the individual and national cultural antecedents of consumer innovativeness. J Mark 63(2):55-69

57. Susskind AM (2004) Electronic commerce and World Wide Web apprehensiveness: an examination of consumers' perceptions of the World Wide Web. J Comput Med Commun. 9(3):JCMC931

58. Swinyard WR, Smith SM (2003) Why people (don't) shop online: a lifestyle study of the internet consumer. Psychol Mark 20(7):567-597

59. Triandis HC (1995) New directions in social psychology. SAGE Publications, Thousand Oaks

60. Van Slyke C, Comunale CL, Belanger F (2002) Gender differences in perceptions of web-based shopping. Association for computing machinery. Commun ACM 45(8):82

61. Van Slyke C, Bélanger F, Johnson RD, Hightower R (2010) Gender-based differences in consumer e-commerce adoption. Commun Assoc Inf Syst 26(1):2

62. World Bank Global FINDEX. https://globalfindex.worldbank.org/. Accessed 1 June 2019
63. Wu SI (2003) The relationship between consumer characteristics and attitude toward online shopping. Mark Intell Plan 21(1):37-44

64. Yeniyurt S, Townsend JD (2003) Does culture explain acceptance of new products in a country? An empirical investigation. Int Mark Rev 20(4):377-396

65. Yoon C (2009) The effects of national culture values on consumer acceptance of e-commerce: online shoppers in China. Inf Manag 46(5):294-301

66. Zhou L, Dai L, Zhang D (2007) Online shopping acceptance model_a critical survey of consumer factors in online shopping. J Electron Commerce Res 8(1):41-63

67. Zhu L, Thatcher S (2010) National information ecology: a new institutional economics perspective on global e-commerce adoption. J Electron Commerce Res 11(1):53-72

\section{Publisher's Note}

Springer Nature remains neutral with regard to jurisdictional claims in published maps and institutional affiliations.

\section{Submit your manuscript to a SpringerOpen ${ }^{\circ}$ journal and benefit from:}

- Convenient online submission

- Rigorous peer review

- Open access: articles freely available online

- High visibility within the field

- Retaining the copyright to your article

Submit your next manuscript at $\gg$ springeropen.com 